\title{
Application of a color education software to improve color aptitude
}

\author{
ERIKA PERGE
}

Abstract. The ability to handle colors smoothly and consciously may be vital to professionals in various fields, including engineers specializing in architecture or design. Education in sciences related to colors and a developed color aptitude are essential. In our experience, many secondary school graduates in Hungary exhibit inadequate competence and need to be trained in both fields by college instructors, thereby laying the foundations for their future professional work. In our paper, we introduce a computer-based method to teach color theory using a self-developed interactive educational software. We also demonstrate the results of a test measuring the efficiency of the software. Our method was shown to be capable of familiarizing students with the basic fields of visual computing, e.g. graphics and image processing.

Key words and phrases: color theory, educational software, development of aptitude.

ZDM Subject Classification: D40, U50, U70.

\section{Introduction}

"What is hardest of all? That which seems most simple: to see with your eyes what is before your eyes." (Johann Wolfgang von Goethe)

In recent years, an increasing number of studies have been published on aptitude development in public education, and favorable trends can be observed in Hungarian educational policy. According to Nagy, "more commitment is necessary to improve skills and aptitudes" [17]. A definition of aptitude in Lénárd's words: a sum of an individual's attributes necessary for a certain task, determining whether the individual is capable of accomplishing that task [15]. Thus, 
practice or application is an important aspect of aptitude. One major concern in today's public education in Hungary is that taught material may not get incorporated into students' general knowledge, thereby limiting its application [4]. Many students lack the aptitude to obtain competent, applicable knowledge.

In many professions - e.g. fine and industrial arts, architecture, marketing as well as visual, publishing or product design and the productive industry in general -, an important aspect of projects is applying the right colors to living spaces, residential areas, products and other items. Engineering, artistic and related professional courses should place sufficient emphasis on the education of color theory as well as its creative application [23], as lacking these abilities may not be compatible with high-standard designing.

According to our own experience, secondary school graduates tend to lack sufficient education and aptitude related to color theory [20]. As instructors of a technical college, we encounter shortcomings especially when teaching architectural and product design, computer graphics and digital image editing. Concerns are present at multiple levels: lack of basic knowledge, failure to organize learned material, missing the ability to match and distinguish colors, poor color perception or aesthetic sense, or an inability to apply theoretical knowledge in practice.

A research program to improve students' color aptitude and knowledge of color theory has been in progress since 2012 at the University of Debrecen, Faculty of Engineering. Students enrolled at the faculty are recruited as subjects to our study, which involves a self-designed, novel development method. Our method of teaching color theory has its roots in applied computer sciences. Any kind of design today is primarily done on a computer, so students need to be informed about the techniques to use colors in a digital environment, color spaces and the types of color coding. Our method proved to be efficient in familiarizing students with certain basic fields of IT sciences, like computer graphics and image processing.

To produce designs and pictures in color, students need to create fine color harmonies. Our aim is to support students' high-level designing or creative projects by developing the required abilities - color aptitude, matching and distinguishing colors - using a self-designed software in teaching color theory. Novelty of the educational method lies in the thematic organization of taught material and the unique application of devices to support the learning process. Research was conducted to measure the efficiency of our method under controlled conditions. We demonstrate the results below. 
Our method to pass information and improve aptitude in color theory is currently in use at a 28-hour course at the University of Debrecen, Faculty of Engineering in the education of students majoring in Architecture, Mechanical Engineering, Civil Engineering, Mechatronics Engineering or Technical Management, as part of the subjects Color dynamics and Expression technique. The method has also been adapted to secondary school level education for students of Fine Arts - specializing in Painting, Graphic Arts or Photography - by instructors working at the Medgyessy Ferenc Grammar School and Secondary School of Art.

\section{Developing abilities to apply knowledge of color theory}

Most achievements in color theory are attributed to prominent scientists in the fields of physics, physiology or psychology in the 19th and 20th centuries. Many researchers of the time showed interest in developing and identifying color systems and in color identification [12].

Three values are necessary and sufficient to unambiguously characterize a color stimulus: hue, saturation/chroma and brightness/lightness. Recently, more and more experimental methods - all rooted in the fundamental attributes of colors - have been developed to improve subjects' ability to distinguish and match colors [1],[11]. An increased industrial demand for these abilities is evident just by looking at the wide variety of tests on the market [2],[13],[14],[16]. Many internationally approved methods are available to detect deficiencies of color vision and measure or improve the ability to match and distinguish colors.

Tests to measure the ability to distinguish colors

- Anomaloscopes (Nagel, LED, Heidelbergi, Tomey, Oculus anomaloscope)

- Pseudoisochromatic tests (spotted plates). Types: Ishihara [27], American Optical, Hardy-Rand-Rittler, Dvorine, F2, Ohkuma,

- Color arrangement tests: These tests involve colored discs that are to be put in the order of their hue. Types: Farnsworth D15, Desaturated D15, Farnsworth-Munsell 100 [7],[26].

- Lamp tests: e.g. Giles-Archer, Lantern and Rodenstock tests

Tests and exercises to measure and improve the ability to match colors (to assess color qualities with high precision)

- ISCC-CAT (Color Aptitude Test) [5],[6].

- HVC test (Luo Graham and Color Curve) [8],[9],[10],[19],[25]. 
- JCAT (Japanese Color Aptitude Test) [28].

The following methods are suitable to practice how to assess color qualities with high precision and identify differences:

- Student Set [29].

- Student exercises [30].

\section{A method to teach color theory and improve aptitude}

Education is an active process in which instructors use various devices to allow taught material to be perceived and grasped by students. In his work "Didactica Magna", Comenius suggests to pass information by sensible experience, a rational approach involving the student's own thoughts or quoting others' views. According to Piaget [21], people need experience revealing unique features of a studied phenomenon. The process of teaching and learning should be organized in a way that allows the student to acquire basic experience on the taught concept through adequate activity.

We also recommend experience-based learning - in other words, before theoretical knowledge is summarized and organized, practice is necessary. In addition to traditional methods, we utilize the capability of computers to display and process colors in our development program. Our educational software supports the development of aptitudes needed to apply knowledge gained on the field of color theory.

\section{Traditional devices used in our cultivating method}

In this section, we discuss how to improve aptitude by traditional means. These include paints such as watercolor, tempera and printing ink, colored lamps, colored paper, printed cards, colored plates and a rotation disc used for blending paint, basically a modified spin dryer.

\section{Developing the ability to distinguish colors}

One of the main goals of our method is to improve students' ability to distinguish colors, allowing them to recognize slight differences in hue, saturation or brightness by regular practice of related exercises. One type of problem students need to solve is comparing color samples of the same hue and different brightness, 
of the same hue and different saturation, of different hue and brightness, or of different hue and the same brightness. Another type of exercise is putting color samples in a decreasing or increasing order of brightness or saturation.

When attempting color comparison or creating color collections during our courses the use of colored paper or printed color cards is encouraged over paint. By this method, a wider range of hue, brightness and saturation values can be applied, as paper is available in great variety and the same color can be reused multiple times with no adverse change in its quality or surface properties. However, as traditional methods require painting or printing a set of samples of defined saturation or brightness for each task beforehand, the number of exercises that can be prepared for a class this way is limited.

\section{Developing the ability to match colors}

"It is known from practice that by blending two or more colors, more can be created, or that any color can be obtained in more than one way. Another practical fact is that any color may be created from the right mixture of correctly chosen primary colors. There are two ways to obtain a specific color from the primary ones: additive and subtractive mixing" [18]. These are the two color mixing theories in chromatics: their application affects our daily life.

When using traditional methods to teach color matching in our course, we make students practice the two ways of color mixing. In the blending of paint colors (subtractive color mixing), we use a color-blending machine converted from a spin dryer. By using only the three primary colors (cyan, magenta and yellow) we can observe and study the formation of mixed colors. Different quantities of the primary colors can be placed on the horizontal plate of the color-blending machine, and the resulting mixture is observed. Three types of printing ink are the most suitable for this task. To mix the color of light sources (additive color mixing), three colored lamps are used, each with a color corresponding to one of the primary colors (red, green and blue). An overlap of two colors produces a brighter result, while the mixture of all three results in white. Using multiple projectors can yield a similar result by projecting the primary colors over one another.

Laws of color mixing are observed through experiments. If color quality falls short in the previously mentioned exercises, paint mixing may produce inadequate, possibly misleading results. In the case of colored lamps, intensity of colors cannot be modified, which limits the options to create colors of any hue. 
Many of the obstacles and limitations encountered when using traditional methods can be overcome by different modules of our teaching software, allowing for a more complete perception of natural laws.

\section{An interactive software to teach color theory}

Electronic devices and computer software have created new possibilities to acquire and pass information. Our aim was to engage students in a way that involves multiple learning channels complementing one another, making it easier to grasp color relationships as they occur in the real world. An important feature of our educational method is an interactive software developed by our group. It may also be used together with professional image-editing software available on the market. Our program assists learning various aspects of color theory normally covered by different scientific fields, supporting comprehension, synthesis and practical application of learned material. It is a valuable asset to students aiming to improve their ability to recognize, distinguish and match colors.

The software consists of three main sections: a theoretical course on color theory, exercises for practice and test questions. Both the theoretical and the practical sections are divided to further modules.

1. Modules of the theoretical section: organs and processes in color vision (basic physiology of the eyes and the brain), basic optics (light, electromagnetic waves, reflection and refraction of light), theories of color mixing (additive, subtractive), major qualities of colors (hue, saturation, brightness), color systems, collections, coding, harmonies, contrast [3],[18],[22].

2. Modules of the practical section: mixing colors in the HSB system, mixing colors in other color systems, matching color stimuli, color harmonies, color contrasts.

3. There are test questions available for the theoretical section and exercises for each type of task covered in the practical section.

To develop the program, we used the Flash ActionScript environment, which combines the efficiency of high level programming languages with spectacular animations. An HTML 4-compatible web browser is required. Test questions are processed by a flash module, and results are submitted to a public server where the data are stored in an SQL database. Proven benefits of our software:

- An opportunity to obtain and organize information efficiently 
- Stimulating: lot of experience may be accumulated on the attributes and effects of colors over a short period of time

- Any conversion between color spaces is possible

- Any combination of colors can be created and its effects are instantly visible

- Real-time changes can be made to building exteriors or interiors, still lifes or other graphic art by applying color harmonies

- Included tests provide a means to check and keep track of progress. An electronic asset in evaluating the efficiency of the learning process is especially valuable when teaching large groups of students, as it spares time, allows for easier comparisons, helps notice the need for remedial activity or talent cultivation and facilitates recognition of problem areas.

Taking all advantages into account, the software can be considered suitable for the development of students' aptitude. Below, we introduce the modules of our software and how to use them. We also demonstrate its advantages through various types of exercises aimed at improving students' color aptitude.

\section{Utilizing the software to cultivate aptitude}

The following modules were used to improve the ability to match and distinguish colors.

\subsection{Color matching}

Our software allows color mixing in the HSB, RGB and CMY systems alike. The aim of these exercises is to test judgment of color qualities.

Color mixing in the HSB system.

The student needs to mix a certain target color matching a sample generated by the computer at a panel on the left side of the screen (see Figure 1). Users can adjust the hue, saturation and brightness level of the right rectangle until they perceive the two colors as identical. Hue is chosen using the color wheel below the rectangles $\left(0-360^{\circ}\right)$, while saturation or brightness can be increased or decreased by the corresponding slider $(0-100 \%)$. The currently black background behind the rectangles can be changed to white, gray or colored. An optional hint can be displayed above, showing the direction of difference $(+$ or -$)$ in hue, saturation 
and brightness values between the original sample and the color mixed by the user.

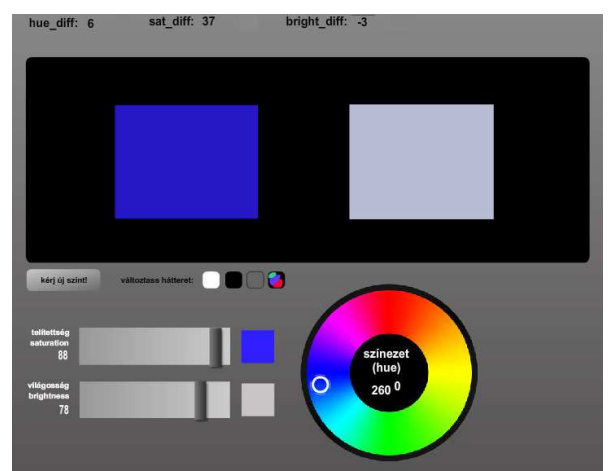

Figure 1. An HSB color mixing interface as seen in the educational software [24]

For the untrained eye of beginners, it can be difficult to notice slight differences in the three qualities of a color, let alone estimate the direction and magnitude of the difference. It is useful to display the hint in the first phase of learning. Students may also observe the HSB code of each color.

\section{Mixing colors in different systems (RGB, CMY, HSB).}

The educational software simulates additive and subtractive color mixing. Students can alter the "intensity" of each light source on the slides, and observe the resulting color along with its color code (see Figure 2). Instructors may demonstrate the laws of color mixing.

The software can provide any primary color in any intensity, ensuring that the target color may be obtained through mixing in any of the three color systems.

\subsection{Improving the ability to distinguish colors}

Our program contains two modules aimed at developing an ability to distinguish colors: "Matching color stimuli" and "Color scale". The goal is to perceive fine differences in color qualities. 


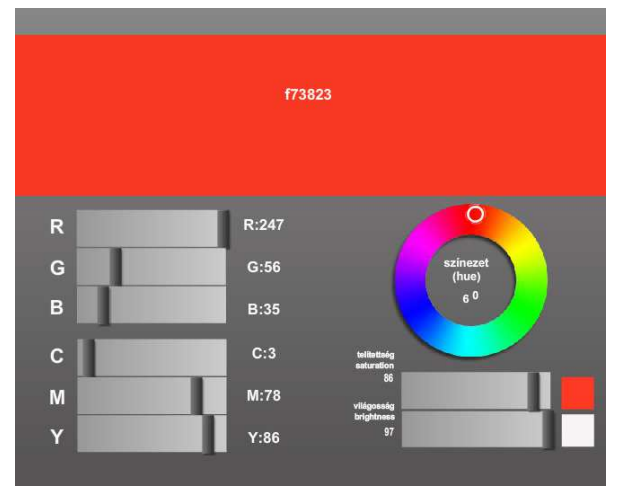

Figure 2. Color mixing in various color systems [24]

Matching color stimuli.

There are many possible experiments to test if the user can correctly match color stimuli, and in each one, either the brightness (Figure 3.a) or the saturation differs (Figure 3.b). The program creates both samples randomly, and the value of difference between the two is also a random number generated within a range that gets narrower with each experiment to increase difficulty.

The task is:

a) to decide which sample is brighter when hue and saturation are constant

b) to recognize the more saturated sample when hue and brightness are constant

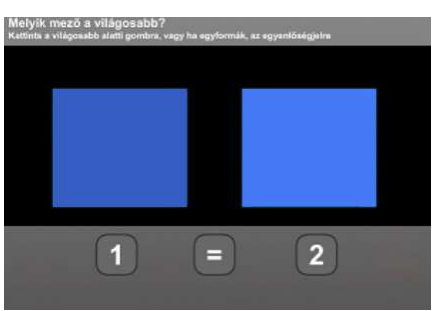

(a)

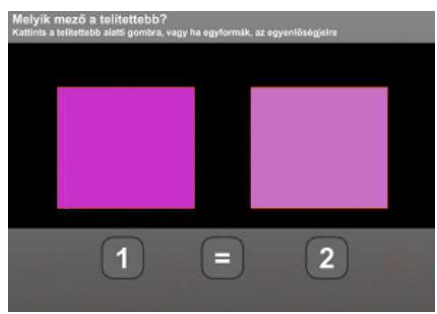

(b)

Figure 3. Matching color stimuli in the educational software [24]

Color scales.

The software generates color patterns and a particular alignment. 
The task is to put samples in decreasing or increasing order of brightness (Figure 4.a) and saturation (Figure 4.b), and then arrange samples within a specific frame according to their position on the dark-bright-saturated-unsaturated double scale (Figure 4.c) The latter exercise is aimed at advanced users, as multiple criteria have to be considered simultaneously.

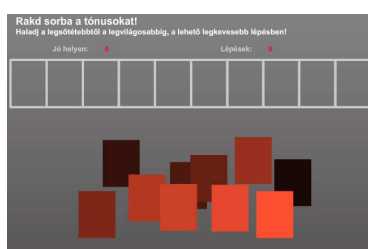

(a)

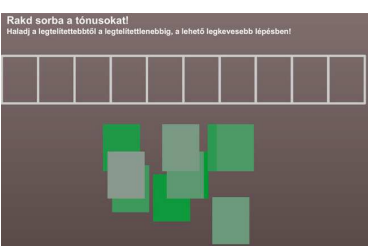

(b)

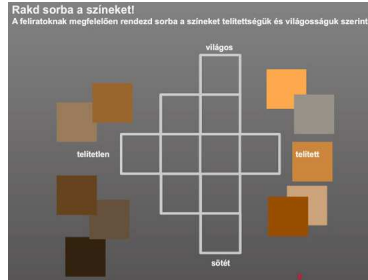

(c)

Figure 4. Saturation and brightness scales in the software [24]

\subsection{Learning application of colors}

Color harmonies.

The software contains information about different types of harmonies and includes a module to test them. Its unique nature lies in its capability to instantly apply a color sample collection - corresponding to the studied type of harmony on a particular theme (see Figure 5). After hue has been chosen from the color wheel, the program generates five color samples with different saturation and brightness levels. Saturation and brightness ranges can be adjusted using the slides. The relationship of colors on building exteriors and interiors, still lifes and other pieces of graphic art can be observed at once.

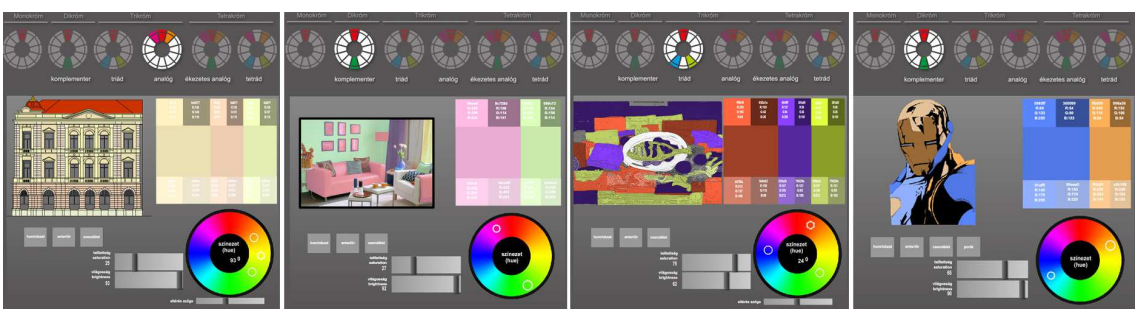

Figure 5. Types of color harmony [24] 


\section{An educational experiment}

Research was conducted at the University of Debrecen, Faculty of Engineering between 2012-2015 with the aim of testing a novel method in teaching color theory and improving the color aptitude of students aged between 19 and 21 years. We studied whether color aptitude of young people at that age is prone to improvement, and we also tested if certain approaches in education showed any difference in their rate of success. We hereby demonstrate our results achieved in the years 2012 and 2013.

The development method we used was aimed at improving students' ability to match and distinguish colors. We tested the following two hypotheses:

I. Our novel educational method is suitable for the development of students' ability to distinguish colors based on their brightness and saturation.

II. Using our educational software as supplementary material in addition to traditional devices increases the efficiency of teaching color matching.

Participating students

A group of 70 students (aged 19 to 20 ) participated in 2012, and a population of 81 (aged 19 to 21) were enrolled in 2013, as demonstrated in Table 1.

Table 1. Size and sex ratio of groups enrolled in our study

\begin{tabular}{ll|c|c|c} 
& & Overall number of participants & Male & Female \\
\hline \hline \multirow{2}{*}{2012} & A & 20 & & \\
& B control & 9 & 13 & 7 \\
& C & 8 & 5 & 4 \\
& D & 33 & 6 & 2 \\
& $\mathbf{7 0}$ & 14 & 19 \\
& & $\mathbf{3 8}$ & $\mathbf{3 2}$ \\
\hline \multirow{2}{*}{$\mathbf{7 0 1 3}$} & A & 41 & & \\
& B control & 40 & 27 & 14 \\
& & $\mathbf{8 1}$ & 30 & 10 \\
& & $\mathbf{5 7}$ & $\mathbf{2 4}$ \\
\hline
\end{tabular}

Groups of participants included students of Architecture, Mechanical Engineering and Technical Management at the University of Debrecen, Faculty of Engineering, as well as students studying Photography, Graphic Arts and Painting at the Medgyessy Ferenc Grammar School and Secondary School of Art (Group D in 2012). They all came in contact with applied color theory at some point during 
their professional training. Using the Ishihara-test to screen for color blindness, we concluded that all students had normal color vision.

Learning methods used in the study

The material taught in classes and the practical and design assignments were identical in all groups (color theory, learning and applying harmony types, color mixing), while educational approaches were different.

Group B served as a control in both years: these students were only taught by traditional methods. In group A, we also used our self-developed educational software and a professional image editor.

In 2012, two further groups were established: group C was taught using the image editor as well as traditional means, while in group D, we used traditional means and our own software without the image editor.

\section{Research methods}

Prior and posterior tests - performed before and after the course, respectively - were conducted to assess improvement. Our task of empirical character was twofold: to measure students' aptitude and to compare results of different groups.

We used four types of problems for testing:

\section{Measuring sensitivity for brightness}

The aim is to make students capable of perceiving ever smaller differences in brightness. The ability to distinguish samples was measured by tests in which students needed to point at their choice. Color pairs are used with 0, 2, 4, 6, 8, 10, and 12 percent difference in brightness. The student has to choose the brighter one (Figure 3.a). Points are added to an overall score: 1 for a correct, and 0 for an incorrect answer. For processing the data, we used the value of difference seen in overall score between prior and posterior tests (brightness-test difference).

\section{Measuring sensitivity for saturation}

By practicing these tests, students should be able to notice slight differences in the saturation of a color. When students think they found the correct answer, they need to point at it. Two color samples are displayed (Figure 3.b), and students have to select their answer from three possibilities: the first sample is more saturated, the second sample is more saturated, the two samples show equal saturation. The color pairs used have $0,5,10,15,20,25$, or 30 percent difference in saturation. 1 point is awarded for a correct answer, and 0 for an incorrect one. For further processing, we used a single value representing the difference of score between prior and posterior tests (saturation-test difference). 


\section{Color mixing}

The aim of these tests is to improve the aptitude to match colors by correctly determining their hue, saturation and brightness. Open tests are used, which are more complex than single-choice problems: students need to mix the color sample seen on the left side of the screen (Figure 1). The module stores the HSB code of the color mixed by the student. The number representing the value of each answer is derived from the difference of corresponding components in the color code of the chosen color and the original sample as an Euclidean distance. The average calculated from these values yields the overall score, and differences seen in scores between prior and posterior tests were used for analysis (color mixing difference).

\section{Arrangement tests}

The aim of these tests is to develop students' aptitude to perceive fine differences in brightness and saturation. The ability to distinguish colors is assessed by tests that involve putting color samples in the correct order of brightness (Figure 4.a), saturation (Figure 4.b), and finally, brightness and saturation at the same time (Figure 4.c) The module does not allow the user to continue to the next question unless the correct solution has been presented. Evaluation is based on the number of steps it takes for students to get to the correct arrangement. Since the first two problems are easier while the final one is harder, a weighted sum was calculated in a ratio of 1:1:2 of each aforementioned problem respectively, and differences in overall scores were used for further analysis (arrangement difference).

\section{Statistical methods used in the educational experiment}

Statistical analysis on the results was performed by SPSS (Statistical Package for Social Science) to verify the efficiency of our educational software by comparing performance of different learning methods. As resulting scores did not show a normal distribution, we used nonparametric statistical tests like the Wilcoxon and the Mann-Whitney test.

\subsection{Comparing results of prior and posterior tests}

A comparison of results students produced in prior and posterior tests served as the basis of analysis. A Wilcoxon test was used to check if medians of scores - for each of the four problem types - were significantly different in each studied 
group. Table 2 shows p values gained from Wilcoxon tests by group and problem type.

Table 2. $\mathrm{P}$ values gained by Wilcoxon tests in each group and problem type (a comparison of prior and posterior tests)

\begin{tabular}{ll|c|c|c|c} 
& & Brightness & Saturation & Color mixing & Arrangement \\
\hline \hline & & & & & \\
2012 & A & 0.000 & 0.000 & 0.000 & 0.000 \\
& B control & 0.017 & 0.008 & 0.086 & 0.008 \\
C & 0.011 & 0.018 & 0.012 & 0.017 \\
D & 0.000 & 0.000 & 0.000 & 0.000 \\
\hline & & & & \\
2013 & A & 0.000 & 0.000 & 0.000 & 0.000 \\
& B control & 0.000 & 0.000 & 0.000 & 0.000 \\
\hline
\end{tabular}

As demonstrated, differences show convincing significance in almost every group for saturation, brightness, color mixing and arrangement problems alike.

The only exception is group B in 2012, where only a trend is apparent $(\mathrm{p}=0.086)$. Lower significance in this group may be attributed to the low size of the population.

\subsection{Comparing performance of different learning methods}

Four groups in 2012 and two in 2013 were taught using different educational approaches. The Mann-Whitney test was applied to find differences in improvement rates. Comparing two groups at a time allowed us to gain more insight on their relationship. Group B (the control group) was compared to all other groups, and all other possible combinations were studied as well. Ranking chosen samples together, we studied whether sums of ranking scores were approximately equal or different. That way, we could determine whether a significant difference was present between the performance of chosen groups. Table 3 contains $p$ values from Mann-Whitney tests (SPSS) and ranking scores. Mean ranks were only compared in case a significant difference was revealed between groups' performances.

Based on the results from 2012, we can make the following observations. Group A (in which the educational software and an image editor were both used) significantly exceeds control group $B$ in three test types $(\mathrm{p}=0.01$ for saturation tests, $\mathrm{p}=0.034$ for brightness tests, $\mathrm{p}=0.008$ for color mixing). In the case of 
Table 3. Results of the Mann-Whitney tests (SPSS) and ranking scores.

\begin{tabular}{|c|c|c|c|c|c|c|}
\hline & & & Brightness & Saturation & Color mixing & Arrangement \\
\hline \multirow[t]{6}{*}{2012} & A-B & $\begin{array}{c}\mathrm{p} \text { value } \\
\text { Mean Rank }\end{array}$ & $\begin{array}{c}0.034 \\
17.22>10.06\end{array}$ & $\begin{array}{c}0.010 \\
17.68>9.06\end{array}$ & $\begin{array}{c}0.008 \\
17.75>8.89\end{array}$ & $\begin{array}{c}0.069 \\
16.95>10.67\end{array}$ \\
\hline & B-C & $\begin{array}{c}\mathrm{p} \text { value } \\
\text { Mean Rank }\end{array}$ & 0.541 & 0.37 & 0.541 & 0.888 \\
\hline & B-D & $\begin{array}{c}\mathrm{p} \text { value } \\
\text { Mean Rank }\end{array}$ & 0.928 & 0.318 & $\begin{array}{c}0.052 \\
14.44<23.42\end{array}$ & 0.546 \\
\hline & A-C & $\begin{array}{c}\mathrm{p} \text { value } \\
\text { Mean Rank }\end{array}$ & 0.182 & 0.199 & $\begin{array}{c}0.021 \\
16.75>8.88\end{array}$ & 0.409 \\
\hline & A-D & $\begin{array}{c}\mathrm{p} \text { value } \\
\text { Mean Rank }\end{array}$ & $\begin{array}{c}0.079 \\
31.78>24.11\end{array}$ & 0.143 & 0.388 & 0.588 \\
\hline & C-D & $\begin{array}{c}\mathrm{p} \text { value } \\
\text { Mean Rank }\end{array}$ & 0.373 & 0.859 & 0.186 & 1 \\
\hline 2013 & A-B & $\begin{array}{c}\mathrm{p} \text { value } \\
\text { Mean Rank }\end{array}$ & $\begin{array}{c}0.00 \\
58.27>23.3\end{array}$ & $\begin{array}{c}0.000 \\
52.01>29.71\end{array}$ & $\begin{array}{c}0.00 \\
53.29>28.4\end{array}$ & $\begin{array}{c}0.00 \\
41>40\end{array}$ \\
\hline
\end{tabular}

arrangement problems, there is only a trend $(\mathrm{p}=0.069)$. This confirms the advantage of using the image editor and our software over the use of only traditional devices.

Group D (the one in which the educational software was applied) outperformed group B in color mixing, the resulting $\mathrm{p}$ value corresponds to a trend $(\mathrm{p}=0.052)$.

There were no significant differences observed between the performance of group B (control) and C (using an image editor but not our own software).

By comparing results from group A, C and D, we could study if there was a significant difference in performance when both our own software and the image editor were used (group A), or just one of the two (group C and D).

In brightness tests, a trend was seen between results of group $\mathrm{A}$ and $\mathrm{D}$ $(\mathrm{p}=0.079)$; group A performed better.

Group A and C produced significantly different results in color mixing tests $(\mathrm{p}=0.021)$. Color mixing seems to have been taught more efficiently when both types of software were utilized.

Difference in performance between the two groups studied in 2013 was revealed to be highly significant $(\mathrm{p}=0.00)$ in all studied fields - saturation tests, brightness tests, color mixing and arrangement - in favor of group A, which benefited from the use of computer-based methods. These results confirm the efficiency of our self-developed software and the professional image editor when used simultaneously. 
In each group that was taught color theory using our own software, a considerable improvement was observed in the results of posterior color matching tests in comparison to prior tests.

\subsection{Comparison by gender}

Dividing all six groups of participants to male and female populations, we applied the Wilcoxon test on each gender-based subgroup independently to see if improvements in performance were significant. Table 4 contains $\mathrm{p}$ values gained from Wilcoxon tests (SPSS).

Table 4. $\mathrm{P}$ values from the Wilcoxon tests (SPSS)

\begin{tabular}{|c|c|c|c|c|c|c|c|c|c|}
\hline & \multicolumn{2}{|c|}{ Brightness } & \multicolumn{2}{|c|}{ Saturation } & \multicolumn{2}{|c|}{ Color mixing } & \multicolumn{2}{|c|}{ Arrangements } \\
\hline & & Male & Female & Male & Female & Male & Female & Male & Female \\
\hline \multirow[t]{4}{*}{2012} & $\mathbf{A}$ & 0.003 & 0.018 & 0.001 & 0.017 & 0.001 & 0.018 & 0.006 & 0.018 \\
\hline & B control & 0.102 & 0.068 & 0.042 & 0.066 & 0.500 & 0.068 & 0.040 & 0.066 \\
\hline & C & 0.027 & 0.18 & 0.043 & 0.18 & 0.028 & 0.18 & 0.046 & 0.18 \\
\hline & D & 0.003 & 0.003 & 0.001 & 0.000 & 0.002 & 0.000 & 0.0046 & 0.003 \\
\hline \multirow[t]{2}{*}{2013} & & 0.000 & 0.001 & 0.000 & 0.001 & 0.000 & 0.001 & 0.000 & 0.001 \\
\hline & B control & 0.000 & 0.016 & 0.000 & 0.005 & 0.000 & 0.074 & 0.000 & 0.025 \\
\hline
\end{tabular}

Lower significance in group B (control) and C in 2012 may be due to low population sizes, especially in the case of the female subgroups (4 and 2 in group $\mathrm{B}$ and $\mathrm{C}$, respectively).

We applied the Mann-Whitney test to reveal differences between male and female students in the increase of their performance over the course. Table 5 demonstrates results of Mann-Whitney tests (SPSS) as seen in different problem types.

Table 5. Results of the Mann-Whitney tests (SPSS) and ranking scores.

\begin{tabular}{ll|c|c|c|c} 
& & Brightness & Saturation & Color mixing & Arrangements \\
\hline \hline \multirow{2}{*}{2012} & p value & 0.350 & 0.496 & 0.972 & 0.213 \\
& Mean Rank & $33.42<37.97$ & $33.99<37.3$ & $35.42<35.59$ & $32.72<38.8$ \\
\hline \multirow{2}{*}{2013} & p value & 0.286 & 0.082 & 0.107 & \\
& Mean Rank & $39.19<45.29$ & $38.05<48.0$ & $38.26<47.5$ & $38.89<46.02$ \\
\hline
\end{tabular}


Results show no significant difference in the performance of the two sexes in saturation or brightness tests, color mixing or arrangement problems. In saturation tests performed in 2013, a trend was present $(\mathrm{p}=0.082)$ in favor of female students.

\section{Conclusions}

Displaying colors on a computer screen was found to be a cost-efficient and flexible supplementary method in the development of students' ability to match and distinguish colors.

Statistical evidence - based on the results of saturation and brightness tests as well as color mixing and arrangement problems - supports our hypothesis about the efficiency of our novel educational method in teaching how to match and distinguish colors to students aged between 19 and 21 .

In our own experience, when looking at students' work and creations in classes, instructors usually had the impression that students' aesthetic sense, analytic thinking in aesthetics, visual communication, creativity, the ability to create and value art, the skill to gain information and solve problems, and color aptitude all showed signs of improvement due to our educational method.

Students taught using computer-based methods (a software to teach color theory and an image editor) significantly outperformed students taught only by regular methods on all studied fields related to color theory. Additionally, within the software-using group, students that used our own educational program seemed to have an advantage in color mixing.

After many years of development and testing, our educational software and novel teaching method was shown to be efficient by designed experiments as well as daily experience and feedback. We recommend its use in professional courses.

Based on the results of further methodological testing, software upgrades involving new problem types are in progress.

\section{References}

[1] A. J. Anderson and A. W. Johnston, Test/Retest and Inter-test Agreement of Color Aptitude Measures, Color Research and Application 40, no. 3 (2015), 224-231.

[2] ASTM, Standard E 1499 (1997), 2009 "Guide for Selection, Evaluation, and Training of Observers" ASTM International, West Conshohocken, PA, 2003, DOI: 10.1520/E1499-97R09, www.astm.org. 
[3] R. C. Atkinson and E. Hilgard, Pszichológia [Introduction to Psychology], Osiris Kiadó, 2005, 131-168 (in Hungarian).

[4] L. Balogh, Képességfejlesztés és iskolai tanulás, Problémák és megoldások, [How to cultivate abilities in education. Problems and solutions], in: Fejezetek a pedagógiai pszichológia köréból I. [Topics in educational psychology I], (L. Balogh and L. Tóth, eds.), Kossuth Egyetemi Kiadó, Debrecen, 2000 (in Hungarian).

[5] F. L. Dimmick, A color aptitude test, 1940 experimental edition, J. Appl. Psychol 39 (1946), 10-22.

[6] F. L. Dimmick, Specifications and Calibration of the 1953 Edition of the Inter-Society Color Council Color Aptitude Test, JOSA 46, no. 6 (1956), 89-93.

[7] D. Farnsworth, The F-M 100 Hue and Dichotomous Tests for Color Vision, JOSA 33 (1943), 568-578.

[8] L. A. Graham and D. R. Carlson, Review and Comparison of Three Old and One New Color Vision Screening Test for Normal Observers, in: Book of Papers, National Technical Conference, AATCC, 1991, 133-138.

[9] L. A. Graham, A New Color Vision Skill Test, Die Farbe 39, no. 1/6 (1993), 89-98.

[10] L. A. Graham and L. Thieme, The HVS Color Vision Skill Test, A Technical Update, in: Proc. SPIE 4421, 9th Congress of the International Colour Association, 2002, DOI: $10.1117 / 12.464738$.

[11] R. Hirschler, J. Gay and D. Ferreira de Oliveira, Field trials of three tests for color vision and color aptitude, in: Proceedings of SPIE, Vol. 4421, 9th Congress of the International Colour Association, (R. Chung and A. Rodrigues, eds.), SPIE, Bellingham, WA, 2002, 323-326.

[12] R. G. Kuehni and A. Schwarz, Color Ordered - A Survey of Color Order Systems from Antiquity to the Present, Oxford University Press Inc., New York, 2008.

[13] R. Lakowski, A critical evaluation of colour vision tests, Br J Physiol Opt. 23, no. 3 (1966), 186-209.

[14] R. Lakowski, Theory and practice of colour vision testing: A review, Brit. J. industr. Med. 26 (1969), 173-189, 265-288.

[15] F. Lénárd, A problémamegoldó gondolkodás, [The problem-solving approach], Akadémiai Kiadó, Budapest, 1978 (in Hungarian).

[16] A. Melamud, S. Hagstrom and I. E. Traboulsi, Color vision testing, Ophthalmic Genetics 25, no. 3 (2004), 159-187.

[17] J. Nagy, Az eredményesebb képességfejlesztés feltételeiról és lehetôségeiről, [Conditions and possibilities for a more efficient skill development], Iskolakultúra 8 (2003), 40-52 (in Hungarian).

[18] A. Nemcsics, Színdinamika [Colour Dynamics], Akadémiai Kiadó, Budapest, 2004, 28-57, 238-322 (in Hungarian).

[19] S. J. Park, S. R. Fernandez and L. Taplin, Evaluation and Correlation of Color Discrimination Abilities, in: Munsell Color Science Laboratory Technical Report, 2000 . 
[20] E. Perge, Using educational multimedia-based software in teaching color theory to students of civil engineering, Teaching Mathematics III. (2012), 103-111, ISBN 978-80-8084-955-9.

[21] J. Piaget, Válogatott tanulmányok, [Selected studies], Gondolat Kiadó, Budapest, 1970 (in Hungarian).

[22] R. Sekuler and R. Blake, Perception, 5 edition, McGraw-Hill Humanities Publisher, 2005, 45-122, 205-240.

[23] C. Sik Lányi, Zs. Kosztyán, B. Kránicz, J. Schanda and M. Navvab, Using multimedia interactive e-teaching in color science, LEUKOS The Journal of the Illuminating Engineering Society of North America 4, no. 1 (2007), 71-82, ISSN 1550-2724.

[24] E. Perge, 01/06/2015, szin.nyomas.hu, szin.nyomas.hu/tesztek.

Test Manuals and Exercises

[25] HVC Color Vision Skill Test - User's Manual, Color Curve Systems Inc., 1998.

[26] D. Farnsworth, The Farnsworth-Munsell 100-Hue Test, Manual, 1957, New edition: Munsell Color, GretagMacbeth, Quick Guide to Operation FM Test, May $1997 .$.

[27] Ishihara's Tests for Colour-Blindness, 24 Plates Edition, Kanehara Co., Tokyo, 1993.

[28] Japanese Color Aptitude Test - manual, Japan Color Research Institute, 1994.

[29] J. T. Long, The New Munsell Student Color Set, 3rd ed., Fairchild books, New York, 2011.

[30] NCS Complete Colour Exercises, 23/05/2015, http://www.ncscolour.co.uk/products /individual_product_pages/colour-exercises.html.

ERIKA PERGE

FACULTY OF ENGINEERING

UNIVERSITY OF DEBRECEN

H-4028 DEBRECEN, TEMET STR. 2-4.

HUNGARY

E-mail: perge@eng.unideb.hu

(Received June, 2015) 